Original Article

\title{
The Effect of Obstacle Training in Water on Static Balance of Chronic Stroke Patients
}

\author{
JaeHyun Jung, PT, MSc1), JiYeun Lee, PT, PhD ${ }^{2)}$, EunJung Chung, PT, PhD²), \\ Kyoung Kim, PT, $\mathrm{PhD}^{1)^{*}}$ \\ 1) Department of Physical Therapy, Daegu University: 15 Naeri-ri, Jinlyang, Gyeongsan-si, \\ Kyeongsangbuk-do 712-714, Republic of Korea \\ 2) Department of Physical Therapy, Andong Science College, Republic of Korea
}

\begin{abstract}
Purpose] This study evaluated the effects of water and land-based obstacle training on static balance of chronic stroke patients. [Subjects] The subjects were randomly allocated to an aqua group $(\mathrm{n}=15)$ and a land group $(n=15)$. [Methods] Both groups trained for 40 minutes, 3 times a week for 12 weeks. Static balance was assessed by measuring the mean velocities of mediolateral (ML) and anteroposterior (AP), and sway area with the eyes closed. [Results] Following the intervention, both groups showed significant changes in ML velocity, AP velocity, and sway area. The static balance of the aqua group was significantly better than the land group. [Conclusion] The results of this study suggest the feasibility and suitability of obstacle training in water for stroke patients.

Key words: Stroke, Aqua, Obstacle training
\end{abstract}

(This article was submitted Aug. 30, 2013, and was accepted Oct. 10, 2013)

\section{INTRODUCTION}

A stroke is the rapidly developing loss of brain function due to a disturbance in the blood supply to the brain. This can be due to ischemia caused by blockage or due to a hemorrhage $^{1)}$. Post-stroke individuals present an array of changes to the neuromuscular system functions, such as muscle weakness, impaired proprioception, abnormal muscle activation patterns, and impaired postural control ${ }^{2}$. Following a stroke, the ability to maintain balance is often reduced, resulting in a greater risk of fall ${ }^{3)}$.

Obstacle crossing performance is a difficult task for many people following stroke ${ }^{4)}$. Because difficulty in stepping over small obstacles may contribute to the high fall rate following stroke, a more detailed understanding of the underlying movement disorders is crucial $^{5}$. Said et al. ${ }^{6}$ found that 13 of 24 subjects with stroke failed to cross an obstacle on one or more occasions: 8 subjects failed once, and 5 subjects failed more than once. Subjects with stroke are unstable, during affected limb support compared with unimpaired subjects.

Aquatic exercise can refer to pool therapy, hydrotherapy, or balneotherapy ${ }^{7}$. Warm water can increase the blood flow, helping to dissipate allogeneic chemicals and enhancing muscle relaxation. The hydrostatic effect of water can alleviate pain by reducing peripheral edema and sympa-

*Corresponding author. Kyoung Kim (E-mail: kykim257@ hanmail.net)

(C2014 The Society of Physical Therapy Science. Published by IPEC Inc. This is an open-access article distributed under the terms of the Creative Commons Attribution Non-Commercial No Derivatives (by-ncnd) License $<$ http://creativecommons.org/licenses/by-nc-nd/3.0/>. thetic nervous system activity ${ }^{8)}$. When exercising in water, buoyancy and the frictional resistance of water have specific mechanical effects on the body. Fluid pressure is exerted equally on all surface areas of a stationary body immersed at a given depth ${ }^{9}$. Furthermore, exercise in water can provide special rehabilitation environments suitable for patients with functional limitation, and assists balance through the resistance of water against the upper limbs, the lower limbs, and the body ${ }^{10)}$. Lee et al. ${ }^{10)}$ divided 34 chronic stroke patients into a water group (17 subjects) and a land group (17 subjects) and conducted the same task-oriented training. The water training group showed significant increases in static and dynamic balance compared to the land group. Noh et al. ${ }^{11)}$ reported, that compared with a conventional therapy group, an aquatic therapy group showed significant improvements in postural balance and muscle strength. The purpose of this study was to examine the effect of obstacle training in water on the static balance of chronic stroke patients.

\section{SUBJECTS AND METHODS}

A total of 30 stroke patients who voluntarily agreed to participate in this study were included. The selection criteria were: more than 6 months since the clinical diagnosis of ischemic or hemorrhagic; ability to walk with or without walking aid for a minimum of $15 \mathrm{~m}$; a Mini-Mental State Examination score greater than $24 / 30^{12}$ ); vision and hearing adequate for completion of the study protocol, as indicated by the ability to follow written and oral instructions during screening; and the capacity to understand and follow instructions. Exclusion criteria were a history of previous stroke or other neurological diseases or disorders; patients 
Table 1. Characteristics of the participants $(n=30)$

\begin{tabular}{lccc}
\hline & & $\begin{array}{c}\text { Aqua group } \\
(\mathrm{n}=15)\end{array}$ & $\begin{array}{c}\text { Land group } \\
(\mathrm{n}=15)\end{array}$ \\
\hline Gender $(\%)$ & Male/Female & $8(53.3) / 7(46.7)$ & $8(53.3) / 7(46.7)$ \\
Age $(\mathrm{y})$ & & $57.2(3.9)$ & $55.6(4.3)$ \\
Height $(\mathrm{cm})$ & & $163.3(2.1)$ & $166.0(3.2)$ \\
Weight $(\mathrm{kg})$ & & $64.1(5.8)$ & $61.6(6.1)$ \\
Months after stroke & & $13.5(2.8)$ & $13.8(4.0)$ \\
Side of hemiplegia $(\%)$ & Right/Left & $9(60.0) / 6(40.0)$ & $9(60.0) / 6(40.0)$ \\
Type of stroke $(\%)$ & Infarction/Hemmorrahge & $4(26.7) / 11(73.3)$ & $6(40.0) / 9(60.0)$ \\
K-MMSE & & $26.5(2.5)$ & $27.3(1.8)$ \\
\hline
\end{tabular}

$\mathrm{n}(\%)$ or mean (SD); K-MMSE, Korean-Mini Mental State Examination

with pusher syndrome (defined as leaning to the hemiparetic side and giving resistance to any attempt at passive correction); terminal illness; or pain, limited motion, or weakness in the non-paretic lower extremity that affected performance of daily living activities (by self-report). Each participant signed an informed consent prior to participation. The subjects were randomly divided into an aqua group (fifteen subjects) and a land group (fifteen subjects). Obstacle training was performed in 40 minute sessions three times per week, over a period of 12 weeks. General characteristics of the aqua group and land group are shown in Table 1.

The pool was $7 \times 3 \mathrm{~m}$ and $1.1 \mathrm{~m}$ in depth. The water temperature was kept at $33-35^{\circ} \mathrm{C}$ for the aquatic exercises. The pool step (Sprint's, US) is made of high-strength plastic, and its top surface a nonslip foothold. Though this tool is made for water, it was also used on land to keep the obstacle the same. In order to implement obstacles and stepping-stones in both water and on land, the IGYM system (ISOPA, Korea) was used together with the pool step. The IGYM system is composed of a round tower, bar and ring, made of plastic. The IGYM system floats in water, so we added a weight to the round top to make it sink in the water. After installing the round towers, they were connected by bars at the height of the holes to make an obstacle. Exercise in a pool can provide various therapeutic benefits.

The obstacle training used in this study was applied after modifying and supplementing the obstacle course used by Mean et $\mathrm{al}^{13)}$. The obstacle training consisted of three subparts, stepping over the IGYM system, going up and down stairs, and crossing over a step. The obstacle training was as follows. Warm-up included upper extremity and lower extremity stretching and range of motion exercises for flexibility (5 minutes). The main exercise included stepping over the IGYM (a height of $10 \mathrm{~cm}$ ), stepping over the IGYM (a height of $20 \mathrm{~cm}$ ), going up and down stairs (a height of $19 \mathrm{~cm}$ ), crossing over a step (a height of $14 \mathrm{~cm}$ ), and turning around a target and returning along the obstacle course. The training was repeated for 30 minutes. Cool down included upper extremity and lower extremity stretching and range of motion exercises for flexibility (5 minutes).

Balance was measured using the Good balance system (Metitur Ltd, Jyväskylä, Finland, 1993). This equipment is used for measuring the static and dynamic balance of the elderly, stroke patients, and general subjects, and is widely used $^{14)}$. Static balance is measured by a force plate as the center of pressure sway path of the body. The mean velocities of mediolateral and anteroposterior sway are calculated, as well as the sway area. The measurements are conducted for 30 seconds with the subjects' eyes open and closed. In this study, static balance was assessed by measuring the mean velocities of mediolateral (ML) and anteroposterior (AP) and sway area with subjects' eyes closed.

The SPSS statistical package, version 12.0, was used for all statistical analyses. The dependent variable was static balance. General characteristics of the subjects and variables followed a normal distribution. The paired t-test was used to determine whether there were changes in static balance between before and after the training. The independent t-test was used for analysis of changes in dependent variables between groups. Results were considered significant at $\mathrm{p}<0.05$.

\section{RESULTS}

Differences in static balance after the interventions are shown in Table 2. The aqua group showed significant differences in ML velocity $(p=0.001)$, AP velocity $(p=0.003)$, and sway area $(p=0.000)$. The land group showed significant differences in ML velocity $(\mathrm{p}=0.004)$, AP velocity $(\mathrm{p}=0.004)$, and sway area $(p=0.000)$. There were significant difference in ML velocity $(p=0.021)$, AP velocity $(p=0.036)$, and sway area $(p=0.049)$ between the two groups after the interventions.

\section{DISCUSSION}

Exercise in a pool can provide various therapeutic benefits. The characteristics of water include hydrostatic pressure, buoyancy, viscosity resistance and temperature. Though hydrostatic pressure can be different in dependent on the depth of water, the equal power is applied to every wet part. When initially starting balance and proprioceptive training, water provides stable support and a comfortable environment, and hydrostatic pressure can activate the peripheral nerves of the trunk and the four limbs, eventually having significant effect, enhanceing of patients' balance $^{15)}$. Owing to buoyancy, patients can participate in ex- 
Table 2. Comparison of static balance with groups and between groups $(\mathrm{n}=30)$

\begin{tabular}{lcccccc}
\hline & \multicolumn{4}{c}{ Values } & \multicolumn{2}{c}{ Change values } \\
\hline \multirow{2}{*}{ Parameters } & \multicolumn{2}{c}{$\begin{array}{c}\text { Aqua group } \\
(\mathrm{n}=15)\end{array}$} & \multicolumn{2}{c}{$\begin{array}{c}\text { Land group } \\
(\mathrm{n}=15)\end{array}$} & $\begin{array}{c}\text { Aqua group } \\
(\mathrm{n}=15)\end{array}$ & $\begin{array}{c}\text { Land group } \\
(\mathrm{n}=15)\end{array}$ \\
\cline { 2 - 7 } & Before & After & Before & After & Before-after & Before-after \\
\hline ML sway velocity $\left({ }^{\mathrm{mm}} / \mathrm{s}\right)$ & $10.4(6.3)$ & $7.1(6.1) * *$ & $9.9(4.5)$ & $8.0(4.0) * *$ & $3.2(1.1) *$ & $1.9(0.4)$ \\
AP sway velocity $(\mathrm{mm} / \mathrm{s})$ & $16.1(7.3)$ & $12.6(6.1) * *$ & $16.7(5.4)$ & $14.1(4.0) * *$ & $3.9(1.6) *$ & $2.4(2.3)$ \\
sway area $\left(\mathrm{mm}^{2} / \mathrm{s}\right)$ & $48.4(16.1)$ & $41.8(11.2) * *$ & $50.2(17.6)$ & $46.8(9.7) * * *$ & $7.0(2.2) *$ & $4.8(1.5)$ \\
\hline
\end{tabular}

Values are means (SD). ML sway velocity, mediolateral sway velocity; AP sway velocity, anteroposterior sway velocity.

${ }^{*} \mathrm{p}<0.05,{ }^{* *} \mathrm{p}<0.01, * * * \mathrm{p}<0.001$

ercise as their joints experience less pressure. Since it can be applied as resistance in accordance with directions of water and body, and also as power that supports movement, the gravity for body can be relieved to promote body support and condition of relaxation. Also weight-bearing and the pressure on the joints can be reduced so that patients can have smoother movement in water than on land ${ }^{16,17)}$. Viscosity resistance is increased when movement in water gets faster and stronger (resistance decreases when movement in water gets slower and smaller), water exercise can be resistance exercise or active assistive exercise depending on the speed of movement, which means that it is possible to adjust effective exercise intensity to enhance patients' balance $^{15,18)}$. Generally, a water temperature of between $33^{\circ} \mathrm{C}: 34^{\circ} \mathrm{C}$ works as an assistive element, increasing skin temperature, expanding blood vessels in the peripheral skin, increasing blood supply, accelerating muscle relaxation, decreasing sensitivity to pain or muscular spasm and enhancing balance function ${ }^{19}$.

This study examined the effect of obstacle training in water on the static balance of chronic stroke patients. Lee et al. ${ }^{10)}$ divided 34 chronic stroke patients into a water group and a land group. The patients received the same task-oriented training for 12 weeks and all subjects were evaluated for static balance using the Good balance system. With eyes closed, both groups showed significant change in ML velocity (water group from $10.1 \mathrm{~mm} / \mathrm{s}$ to $6.6 \mathrm{~mm} / \mathrm{s}$, land group from $10.6 \mathrm{~mm} / \mathrm{s}$ to $7.4 \mathrm{~mm} / \mathrm{s}$ ) and AP velocity (water group from $13.1 \mathrm{~mm} / \mathrm{s}$ to $9.2 \mathrm{~mm} / \mathrm{s}$, land group from $13.7 \mathrm{~mm} / \mathrm{s}$ to $10.4 \mathrm{~mm} / \mathrm{s}$ ). In this study, static balance was assessed as the mean velocies of ML, AP, and sway area with the eyes closed. Both groups showed a significant change in ML velocity (aqua group from $10.39 \mathrm{~mm} / \mathrm{s}$ to $7.08 \mathrm{~mm} / \mathrm{s}$, land group from $9.93 \mathrm{~mm} / \mathrm{s}$ to $7.99 \mathrm{~mm} / \mathrm{s}$ ), AP velocity (aqua group from $16.08 \mathrm{~mm} / \mathrm{s}$ to $12.59 \mathrm{~mm} / \mathrm{s}$, land group from $16.65 \mathrm{~mm} / \mathrm{s}$ to $14.10 \mathrm{~mm} / \mathrm{s}$ ), and sway area (aqua group from $43.39 \mathrm{~mm}^{2} / \mathrm{s}$ to $41.79 \mathrm{~mm}^{2} / \mathrm{s}$, land group from $50.23 \mathrm{~mm}^{2} / \mathrm{s}$ to $46.79 \mathrm{~mm}^{2} / \mathrm{s}$ ). The Static balance of the aqua group was significantly better than that of the land group, a result that is in agreement with the findings of previous research. It is considered that every muscle of both directions could have balanced development due to viscosity of water after the balanced development of extensor muscle and flexor muscle when viscosity resistance is caused in the opposite side of the movement by resistance of water in case of up/ down/left/right exercise without getting affected by gravity in water. Owing to the dynamic help of water through hydrostatic pressure and buoyancy when exercising in water, exercise was continued until subjects fell after passing the limit of stability, while the exercise of the land group was performed under safe conditions to prevent subjects falling.

Bassile et al. ${ }^{20}$ ) reported that obstacle training significantly improved the gait function of individuals with chronic stroke. Said et al. ${ }^{21)}$ reported that modified obstacle crossing reduced the risk of a trip due to toe contact for stroke patients. The findings of previous studies agree with the results of the present study that obstacle training both in water and on land are significantly improves balance function and walking speed, which is considered to support reliability and suitability of the intervention program. We consider that future intervention programs for patients need to include training that can cope with daily hazards and complex environments, such as passing obstacles while walking and walking on stairs. Especially, training in water can be conducted for many patients as it can be easily performed by patients with various illnesses of every age group, and impacts on joints can be reduced by the buoyancy effect of water.

\section{ACKNOWLEDGEMENT}

This research was supported by a Daegu University Research Grant, 2011.

\section{REFERENCES}

1) Sims NR, Muyderman H: Mitochondria, oxidative metabolism and cell death in stroke. Biochim Biophys Acta, 2010, 1802: 80-91.

2) Peurala SH, Konoen P, Pitkanen K, et al.: Postural instability in patients with chronic stroke. Restor Neurol Neurosci, 2007, 25: 101-108. [Medline]

3) Nyberg L, Gustafson Y: Fall prediction index for patients in stroke rehabilitation. Stroke, 1997, 28: 716-721. [Medline] [CrossRef]

4) Said CM, Galea MP, Lythgo N: People with stroke who fail an obstacle crossing task have a higher incidence of falls and utilize different gait patterns compared with people who pass the task. Phys Ther, 2013, 93: 334-344. [Medline] [CrossRef]

5) Forster A, Young J: Incidence and consequences of falls due to stroke: a systematic inquiry. BMJ, 1995, 311: 83-86. [Medline] [CrossRef]

6) Said CM, Goldie PA, Patla AE, et al.: Obstacle crossing in subjects with stroke. Arch Phys Med Rehabil, 1999, 80: 1054-1059. [Medline] [CrossRef]

7) Kamioka $\mathrm{H}$, Tsutani $\mathrm{K}$, Okuizumi $\mathrm{H}$, et al.: Effectiveness of aquatic exercise and balneotherapy: a summary of systematic reviews based on randomized controlled trials of water immersion therapies. J Epidemiol, 2010, 20: 2-12. [Medline] [CrossRef]

8) Gabrielsen A, Videbaek R, Johansen LB, et al.: Forearm vascular and neu- 
roendocrine responses to graded water immersion in humans. Acta Physio Scand, 2000, 169: 87-94. [Medline] [CrossRef]

9) Ariyoshi M, Sonoda K, Nagata K, et al.: Efficacy of aquatic exercises for patients with low-back pain. Kurume Med J, 1999, 46: 91-96. [Medline] [CrossRef]

10) Lee DJ, Ko TS, Cho YM: Effects on static and dynamic balance of taskoriented training for patients in water or on land. J Phys Ther Sci, 2010, 22 331-336. [CrossRef]

11) Noh DK, Lim JY, Shin HI, et al.: The effect of aquatic therapy on postural balance and muscles strength in stroke survivors - a randomized controllded pilot trial. Clin Rehabil, 2008, 22: 966-976. [Medline] [CrossRef]

12) Folstein MF, Folstein SE, McHugh PR: "Mini-mental state" A practica method for grading the cognitive state of patients for the clinician. J Psychiatr Res, 1975, 12: 189-198. [Medline] [CrossRef]

13) Means KM, O'Sullivan PS: Modifying a functional obstacle course to test balance and mobility in the community. J Rehabil Res Dev, 2000, 37 621-632. [Medline]

14) Era P, Schroll M, Ytting H, et al.: Postural balance and its sensory-motor correlates in 75 year old men and women: a cross national comparative study. J Gerontol A Biol Sci Med Sci, 1996, 51: M53-M63. [Medline] [CrossRef]

15) Bandy WD, Sanders B: Therapeutic exercise: techniques for intervention, Philadelphia: Lippincott Williams \& Wilkins, 2001.

16) Heyneman CA, Premo DE: A 'water walker' exercise program for the elderly. Public Health Rep, 1992, 107: 213-217. [Medline]

17) Takeshima N, Rogers ME, Watanabe E, et al.: Water-based exercise improves health-related aspects of fitness in older women. Med Sci Sports Exerc, 2002, 34: 544-551. [Medline] [CrossRef]

18) Jamison L, Ogden D: Aquatic therapy using PNF patterns. Sprint Aquatics, 2003.

19) Skinner AT, Thomson AM: Duffield's exercise in water. Philadelphia: Bailliere Tindall, 1989.

20) Bassile CC, Dean C, Boden-Albala B, et al.: Obstacle training programme for individuals post stroke: feasibility study. Clin Rehabil, 2003, 17: 130136. [Medline] [CrossRef]

21) Said CM, Goldie PA, Patla AE, et al.: Effect of stroke on step characteristics of obstracle crossing. Arch Phys Med Rehabil, 2001, 82: 1712-1719. [Medline] [CrossRef] 